\title{
Article \\ Cycling Master Plans in Italy: The I-BIM Feasibility Tool for Cost and Safety Assessments
}

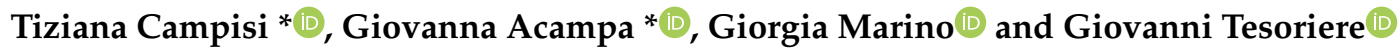

Faculty of Engineering and Architecture, Kore University of Enna, Cittadella Universitaria, 94100 Enna, Italy; giorgia.marino001@unikorestudent.it (G.M.); giovanni.tesoriere@unikore.it (G.T.)

* Correspondence: tiziana.campisi@unikore.it (T.C.); giovanna.acampa@unikore.it (G.A.)

Received: 3 May 2020; Accepted: 28 May 2020; Published: 9 June 2020

\begin{abstract}
Interest towards urban micromobility has been growing lately, and it will now increase further due to the measures used against COVID-19. It is recommended to avoid close contact to prevent contagion. Municipalities have been called to implement wider cycling networks so that people may go to their work place by cycling rather than by using public transport. This paper focused on cycling path design using an infrastructure-building information model (I-BIM). The issue covered was how to connect cost and safety requirements in the first steps of the project. We set a methodology that gives, after identifying the intervention area and defining the available economic resources, the key elements needed to design possible cycle path solutions. It guides the designer step-by-step, starting from basic assumptions related to a cycle path's location (urban/non-urban), budget (by range), and safety (according to Bicycle Compatibility Index BCI and Bicycle Level of Service (BLOS) index), up to the definition of preferred options in terms of materials to be selected. As a case study, we implemented this methodology in the old city center of Catania in Sicily (Italy), designing a cycle path that connects the city center with the existing cycle path on the coast, while aligning with safety requirements within budget constraints.
\end{abstract}

Keywords: BIM; I-BIM; cycle path; cost

\section{Introduction}

The COVID-19 emergency has resulted in measures restricting people's movement, and almost completely blocking transport systems and urban mobility. Complying with the containment measures and, more specifically, to the regulations that called for keeping at least a distance of $1.8 \mathrm{~m}$ (or 6 feet) [1] from other persons meant reducing the services provided by public transportation, meaning the population has needed to opt for traveling using their own transport vehicles. The WHO (World Health Organization 2020) encouraged people to use bicycles or to walk under these circumstances. It confirmed that doing so would lead to physical distance being kept while the minimum requirement for daily physical activity can still be met, which can otherwise be more difficult due to increased teleworking and limited access to sports and other recreational activities during the COVID-19 emergency. In March-April 2020 in Italy, population mobility in all its forms was almost zero. In the peak of the pandemic, this reduction reached about 34\% [2], whereas in the following months (April-May 2020), an increase in use of bikes was reported thanks to the incentives for purchasing classic and/or electric bikes in cities with more than 60,000 inhabitants. Governments are expected to pay increasing attention to this mobility issue, and are trying to implement policies that favor sustainable mobility by using funds to promote the upgrading or the design of cycle paths. Another big challenge for policymakers is to provide an appropriate public transport service that is able to match consumer demand through a constant monitoring of people's mobility by using apps [3]. It is now all the more necessary to reformulate the available urban space in order to create a network of 
smart mobility paths on roadways, to connect each city's main attractions, and to host all types of light mobility. The BIM [4] (building information modeling) methodological approach, based on sharing and interoperability, opens up a potential range of applications in the field of infrastructure design. In this case, we used an infrastructure-building information model (I-BIM). So far, it has been mostly used in the design phase, to visualize the project in $3 \mathrm{D}$, or at most to manage large infrastructures. Little research has been carried out regarding its implementation in the phase that precedes the project, which would meet the need to compare different project ideas, including alternatives that are still in an embryonic phase.

The proposal here is to introduce I-BIM when the design hypothesis is at an early stage of definition, as a tool that allows the selection of alternatives that ensure, within an established budget, an adequate level of safety. The attention, therefore, is here focused on the typical first phase in the design process: the technical-economic feasibility examination. We have analyzed a case study involving Catania. Over the years, the city has adopted a model whose low quality and environmental standards created a metropolitan environment that is among the least sustainable in Europe. This paper shows step by step how to integrate, in a BIM environment, an evaluation system that correlates the morphological characteristics of the path, safety parameters, and cost variation with possible road sections.

\section{Cycling Urban Planning}

The spread of different transport systems, especially those with high technology and low environmental impacts, could help in achieving smart city goals by using information technology [5].

In the literature, several studies have focused on the definition and the management of services related to the transport system. Generally, they considered the global system in the first step and subsequently considered the addition of more details for each mode of transport, through a top-down approach. The evolution of telematics is based on the data and information that must be collected, evaluated, and grouped for later steps. In this context, intelligent technologies linked to the Internet of things (IoT) enable a simple and effective collection of information and data processing directly from the "things" and devices included in the information flow network [6]. Furthermore, an emerging trend in this direction is the integration of on demand modes in combination with public transport, leading to the concept of mobility as a service (MaaS) $[7,8]$.

In cycling infrastructure design, this concept allows us to define criteria and methodologies that are useful for analyzing challenging situations [9]. The development of cycling in urban areas allows the public to move independently in mainly flat areas over short distances (less than $5 \mathrm{~km}$ ) and to connect, for longer distances, with the public transport system [10]. Bicycles are an alternative to polluting vehicles. They cause a reduction in air and noise pollution levels, also allowing people to take alternative and more pleasant routes through green areas and historical centers. Cycling infrastructure has spread unequally throughout Europe due to orographic issues and citizens' varying willingness to use it. However, new technologies have increased the popularity of cycling, such as the introduction of assisted cycling or the evolution of sharing mobility [11-13]. Both in Italy and across Europe at large, so-called Biciplans have been drawn up, which aim to design cycle infrastructures: they are medium-term mobility plans that identify the main cycle routes to be implemented and foresee possible future cycling services, such as protected parking, cycle rentals, and intramodality with public transport [14,15].

\section{I-BIM and Its Infrastructure Applications}

BIM, the acronym for "building information modeling", is mostly defined as a process involved in the design, execution, and maintenance of a construction that uses an information model; in other words, IBM is a model that contains all the information concerning the entire life cycle of a construction, from project to building, until demolition and disposal [16,17].

From the earliest stages of the process, BIM can be used by designers to shape their ideas, thanks to graphic processing tools that easily convey visual and spatial information regarding the modeled 
object [18]. Simulation within a BIM environment allows users to verify if the design will function as intended, while abiding to the design requirements, and to identify any interference between planned objects [19]. The system's interoperability brings closer collaboration among the different actors in the process, which becomes more efficient as digital data and information are shared. In addition, the automatic calculation of the materials' required quantities provides very accurate cost estimations [20]. In practice, during the design phase, only the estimated construction cost is assessed, usually on the basis of an estimated metric calculation of the items involved. Hardly ever is the global cost of a construction calculated, as this implies that a large number of elements are well known. By global cost $\left(C_{g}\right)$ we mean all the expenses that must be incurred during the useful life of an architectural work from its conception, to its construction and management. Its function is (1):

$$
C_{g}=\frac{C_{p}+\sum_{A}^{i} C_{m i}+C_{g e i}}{q^{n}} \pm V_{r}
$$

where:

- $\mathrm{C}_{\mathrm{p}}$ is production cost, and includes the value of the area on which it is built, construction costs, design costs, financial costs, and any advertising promotion costs;

- $\mathrm{C}_{\mathrm{m}}$ is the cost for ordinary and extraordinary maintenance, i.e., useful for conservation;

- $\mathrm{C}_{\mathrm{ge}}$ is the management cost, from energy costs to those necessary for cleaning;

- $\mathrm{V}_{\mathrm{r}}$ is the residual value or the cost of final disposal;

- $1 / \mathrm{q}^{\mathrm{n}}$ is the discount coefficient;

- $\mathrm{n}$ are the years of the building's life cycle.

The global cost, as well as any other elements, can be monitored and controlled easily by BIM tools. The acronym I-BIM (infrastructure-building information modeling) is used in the AEC (acronym of Architecture, Engineering and Construction) sector in reference to infrastructure BIM applications. BIM platforms allow the management of a large set of inhomogeneous data, and bring crucial support in creating a "container" of topographic data, laser scanner surveys, and artefact characteristics; all this information must be homogenized [21]. In particular, the BIM system can generate a three-dimensional model of an infrastructure, including characteristic elements (stratigraphy of superstructures and foundations, water drainage networks, subservices, ancillary works, etc.), simultaneously highlighting the relationships with the surrounding environment [22]. There is no international standard to classify infrastructure, but referring to the approach introduced d by McGraw-Hill, Bentley, and Halpin, reported by Dell' Acqua [23], the most important types of infrastructures can be classified (see Table 1) in 13 categories and 5 domains, which are:

- Transport infrastructure: bridges, roads, railways, tunnels, airports, ports, and harbors.

- Energy infrastructure: wind power plants; hydroelectric power plants; nuclear power plants; substations; electricity grids; oil and gas extraction plants; copper, iron, and coal mines.

- Public utility infrastructure: distribution of natural gas, electricity and water, sewerage, sewage treatment systems, and oil pipelines.

- Recreational facility infrastructure, such as parks or playing grounds.

- Water management infrastructure, such as white water and waste water facilities, dams, canals, and embankments.

The most important domain is transport infrastructure, which can be sorted into five categories: (I) bridges, (II) roads, (III) railways, (IV) tunnels, and (V) airports/ports/approaches [23].

I-BIM is mainly employed to get the so-called I-BIM uses, as defined by Kreider, who identified the 15 applications most popular in research publications and projects. (Table 1) [24]. They refer to all the phases of a construction process, from concept design to construction, maintenance, and management.

The functionalities of the virtual models are closely related to the BIM uses chosen, from visualization, to structural analysis, to infrastructure management, and so on. Even if virtual BIM 
models applied to the infrastructure categories are mainly developed for visualization, others are beginning to be implemented. In road design, the use of BIM technology in each stage from early design to management has made it possible to exploit the data stored not only for quantity calculations, but above all for traffic simulations. The system can predict the flow of vehicles on the motorway, as well as strategies to avoid potential congestions. Some I-BIM (infrastructure-BIM) applications in the road field create a "road information model", equipped with plans, profiles, and cross-sections or interchangeable formats for better data sharing [25]. In tunnel construction, the first major project to use BIM was located in London (Crossrail, $21 \mathrm{~km}$ of tunnels, 37 new stations) and the second in Stockholm (bypass, $18 \mathrm{~km}$ of tunnels, 3 lanes in each direction, the largest road tunnel project in the world) [26]. BIM helped to implement more flexible and efficient methods for parametric modeling of excavations, piles, underground works, and all other typical infrastructural elements [27]. The advantages brought by BIM in simulations, interference analysis, and works' virtual inspections are significant, yet it is rarely employed. In bridges and viaducts, data collected from temperature sensors have been exploited to assess the state of bridges under different climatic conditions; besides, standard patterns for design, geometric modeling, and management have been developed [28-30]. As for cycling infrastructure, simulations in BIM environments have still not been carried out. Scientific publications on this topic have mainly concerned cost-benefit analyses [31,32].

Table 1. BIM uses.

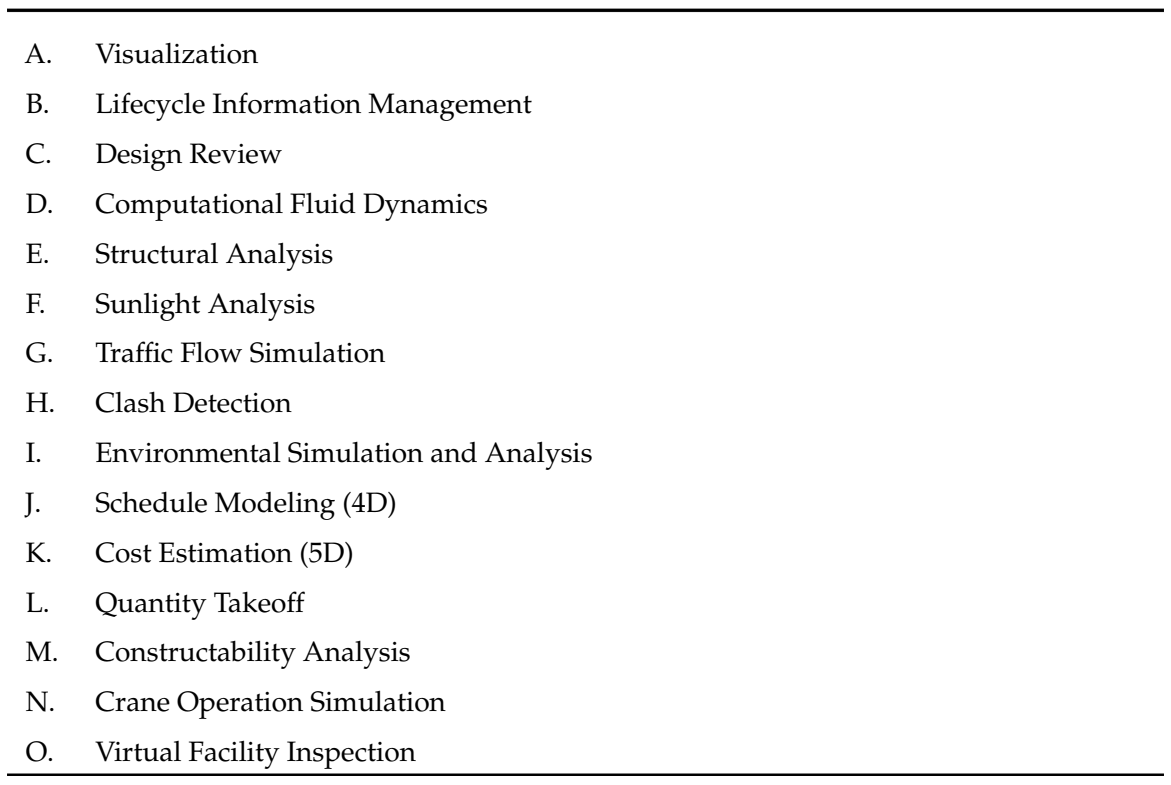

\section{Methods}

Referring to the previous chapter, our research falls within the domain of transport infrastructure, and in particular within the second category, the road. Yet, the model here developed in the BIM environment is meant to perform different BIM uses than those listed in Table 1. We propose the BIM uses of project planning (a pre-A), which can allow actors of process to better analyze the possible alternatives at a very early stage. The team will thus be able to verify better the soundness feasibility of a hypothesis, put forth at the beginning of the process. Referring to the Italian legislation, and more precisely to the Public Procurement Code (Legislative Decree 50/2016) [33], the technical and economic feasibility of a project identifies the solution "that has the best relationship between costs and benefits for the community, in relation to the specific needs to be met and the services to be provided", and "also indicates the performance characteristics, the measures to compensate for the environmental impact, as well as the cost limits of the infrastructure to be built at a level that allows the identification both of 
the route and the necessary environmental impact mitigation works" [33]. This paper introduces an applicable methodology on selecting possible cycle path solutions in the BIM environment.

Once the intervention's scope has been defined, the methodology provides the designer with possible alternative combinations of typical cycle lanes, evaluating them from a safety point of view and, depending on the budget, select a flooring package among those proposed. Once all parameters are loaded into the BIM software, different hypotheses may be compared, choosing the most suitable to abide at the best to all the necessary requirements. The proposed methodology is divided in 7 phases:

1. Location. Cycle routes can be located in urban and suburban areas. The design of cycle networks must take into account this element, guaranteeing the cyclist maximum usability and permeability of road infrastructure. Moreover, the design of routes for slow mobility must be correctly inserted in the landscape. In urban areas, particularly significant are the so-called areas 30 , where vehicles' speed cannot exceeding $30 \mathrm{~km} / \mathrm{h}$, and restricted traffic zones (ZTL as they care called in Italy), even if in other areas the allowed speed may be higher, such as in the $30-50 \mathrm{~km} / \mathrm{h}$ range. In suburban areas, instead vehicles are normally allowed to move at speeds in the range of $50-70 \mathrm{~km} / \mathrm{h}$. National and European experiences on the design and construction of urban cycle paths have shown that standard costs can be adopted. In fact, in the absence of geological problems, it is possible to hypothesize a design with a single substrate layer for both infrastructures. In suburban areas, on the other hand, it is often necessary to construct cycle paths from scratch and related costs depend heavily on eventual works at different altitudes (bridges, cantilevered constructions, etc.). Therefore, it is possible to define three different categories of areas in which cycle paths are to be added:

- $\quad$ A1_Urban area with speed $<30 \mathrm{~km} / \mathrm{h}$, where cycle paths serve urban or residential areas;

- A2_Urban area with speed $30-50 \mathrm{~km} / \mathrm{h}$, where there is normally a promiscuous presence of vehicles and high presence of pedestrians and cyclists. There are often commercial activities and schools. Parks, tourist areas, along the sea or along the river, often fall in this category;

- A3_Urban area with speed $50-70 \mathrm{~km} / \mathrm{h}$, including ring roads and extra-urban roads.

2. Economic availability. The budget for the cycle path is a piece of data of major importance. To assess it, not only construction costs should be considered, but also the costs related to management and maintenance, such as the possible reconstruction of the pavement, adjustments of public lighting, street green spaces, and rainwater conveyance systems in the existing sewage network. Depending on the available budget, it will be possible to choose the best solution considering the quality-price ratio (QPR).

3. Cycle routes selection. Considering the different location, it is possible to identify three different categories related to the urban and nonurban environment with different speeds, as mentioned above (A1, A2, A3). Besides, cycle routes can be located close to the parking lots (B1) and to residential accesses or where those are not there (B2). From the geometric-functional point of view, the presence of a dedicated lane (L1) or a promiscuous cycle-pedestrian lane (L2) must be taken into account. Furthermore, the direction of the cycle flow with respect to the vehicle, either in the same (D1) or in the opposite direction (D2), is to be taken into account. The combination of these parameters provides the types of cycle infrastructure shown in Table 2. 
Table 2. Different geometric combinations.

\begin{tabular}{|c|c|c|c|c|c|c|}
\hline \multirow{3}{*}{ Combination } & \multicolumn{2}{|c|}{ Parking Area Closed to Cycle Path } & \multicolumn{2}{|c|}{ Type of Lane } & \multicolumn{2}{|c|}{ Motorized Vehicle Lane } \\
\hline & B1 & B2 & L1 & L2 & D1 & D2 \\
\hline & Presence & Absence & Dedicated Lane & Promiscuous Lane & One Direction & Double Direction \\
\hline $\mathrm{R} 1$ & $\bullet$ & & & $\bullet$ & $\bullet$ & \\
\hline $\mathrm{R} 2$ & & $\bullet$ & & $\bullet$ & $\bullet$ & \\
\hline $\mathrm{R} 3$ & & $\bullet$ & $\bullet$ & & $\bullet$ & \\
\hline $\mathrm{R} 4$ & $\bullet$ & & $\bullet$ & & $\bullet$ & \\
\hline $\mathrm{R} 5$ * & $\bullet$ & & $\bullet$ & & & $\bullet$ \\
\hline $\mathrm{R} 6$ * & $\bullet$ & & & $\bullet$ & & $\bullet$ \\
\hline $\mathrm{R} 7$ * & & $\bullet$ & $\bullet$ & & & $\bullet$ \\
\hline $\mathrm{R} 8$ * & & $\bullet$ & & $\bullet$ & & $\bullet$ \\
\hline
\end{tabular}

* secondary design choice, to which it is necessary to add the presence of dividing elements for adequate safety.

At the national Italian level, considering the presence or absence of neighboring car parks on the roadside, the most common geometries are the following shown in Figure 1:

- Cycle paths completely separated from streets, (L1) with one (D1) or double direction (D2): where the lane is separate from motor vehicles and from pedestrians, by means of suitable obstacles or horizontal separation signs. The combinations linked to this category are titled R4 (one direction) and R5-R7 (double direction).

- Cycle paths on dedicated lane of roadway (L1) with one direction (D1): the cycle path has here the same direction as the vehicle lanes, is usually located on the right side and is characterized by a separation element i.e., a longitudinal delimitation strip or curbs. The combination R3 refers to this category.

- Cycle paths on dedicated lanes on sidewalk (L1) with one (D1) or double direction (D2): they are located on the side adjacent to the roadway and are built if there is a suitable width, which does not create problems for pedestrian flow. The combinations linked to this category are titled R3 and R5.

- Promiscuous paths (pedestrian + cyclist) (L2): they are usually built in parks or areas with mainly pedestrian traffic, in the event that the width of the roadway or the low cyclist flows do not require the construction of specific cycle paths. The combinations R1, R2, R6, and R8 belong to this class.

- Promiscuous path (motorized vehicle + cyclist) (L2): this solution, envisaging that vehicles and bicycles use the same lane, is the most risky for cyclists. It is necessary to design specific measures (i.e., raised pedestrian crossings or speed cruise sensors) that reduce the problems due the difference in speed among the two traffic components (bike + motorized vehicle). These types are defined by $\left(^{*}\right)$. These solutions are generally to be discarded or limited.

Cycle paths with two adjacent reserved lanes may be designed in the following cases:

- On the pedestrian lane, if the cycling traffic is more intense than the pedestrian; in this case, these are lanes with one side for each direction of travel, generally located in the middle of the road;

- On the roadway, in this case, these are cycle lanes, located to the right of the roadway with the same direction of travel as the vehicles. This solution is mandatory when the cycle flow exceeds $1200 \mathrm{units} / \mathrm{h}$, for at least two peak periods of not less than fifteen minutes in $24 \mathrm{~h}$. 


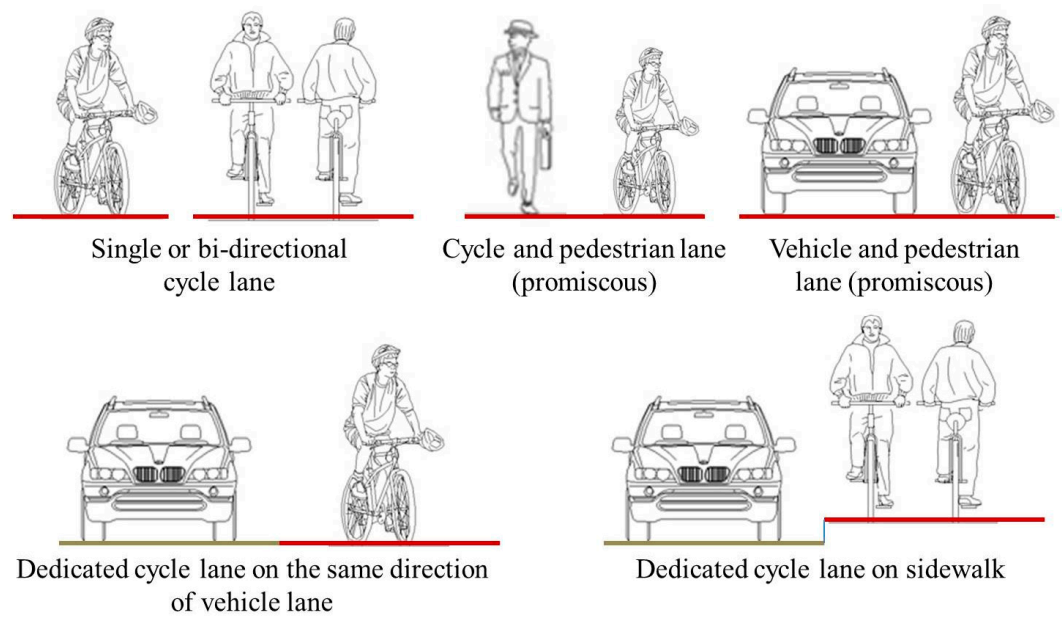

Figure 1. Different type of cycle paths.

The direction of the cycle flow must always be according to that of the vehicles, unless there are separation works, such as islands or not surmountable curbs, especially for categories $\left(^{*}\right)$. This separation element reduces the risk of crashes between vehicles and bikes that occur when they move in the opposite direction, and avoids possible improper use of the lane (e.g., trespassing of heavy vehicles on the cycle lane). In Italy, the design choice must comply with specific standard no. 208 of the 1991 "Interventions for the construction of cycle and pedestrian itineraries in urban areas" and must also comply with the CNR (National Research Council of Italy) standards, as well as the ministerial decree 557/1999 "Regulation containing rules for the definition of the technical characteristics of the cycle paths". Following the aforementioned standards, Table 3 below classifies the design combinations into admissible, preferable, and not allowed/rarely implemented. Furthermore, once a budget is set, the solutions are defined considering a low (green), medium (yellow), or high (red) value. This range was set considering the recent national completed projects. It should be noted that the low category includes projects with a budget (estimated for $1 \mathrm{~km}$ of lane) between 20000,00-30000,00 euros, the middle category linked to $30000,00-40000,00$ euros and the high category with budgets $>40000,00$ euros.

Table 3. Geometric combinations for cycle path plan and design.

\begin{tabular}{|c|c|c|c|}
\hline Area & Possible Combination & Preferable Combination & $\begin{array}{c}\text { Combinations } \\
\text { Rarely Implemented/Not Allowed }\end{array}$ \\
\hline \multirow{3}{*}{ A1 } & $\mathrm{R} 1$ & & \multirow{3}{*}{ n.v. } \\
\hline & $\mathrm{R} 2$ & & \\
\hline & R3 & D? & \\
\hline \multirow{4}{*}{ A2 } & \multirow{3}{*}{ R3 } & $\begin{array}{l}\text { R3 } \\
\text { R4 }\end{array}$ & * R5 \\
\hline & & & * R6 \\
\hline & & & * R7 \\
\hline & $\mathrm{R} 4$ & & * R8 \\
\hline \multirow{2}{*}{ A3 } & R3 & & * R5 \\
\hline & $\mathrm{R} 4$ & & * R7 \\
\hline
\end{tabular}

4. Standard design definition. The design and analysis procedure of cycle routes must be conducted in relation to the following technical-functional aspects: 
- Geometrical aspect of the roadway: the geometric standards to be guaranteed, in accordance with travel speed measures, are linked to the section width, the longitudinal slope, the radii of the curves, and the visibility distance. In detail, the minimum values to be respected (in accordance with ministerial decree 557/1999 "Regulation containing rules for the definition of the technical characteristics of the cycle paths") are shown in the Tables 4-6:

Table 4. Cycle path width.

\begin{tabular}{lc}
\hline \multicolumn{1}{c}{ Minimum Width } & $\mathbf{( c m )}$ \\
\hline Cycle path width single lane & 125 \\
Cycle path width double lanes (one or double direction) & 250 \\
Cycle path width single lane and lateral curbs & 125 \\
Cycle path width double lanes and lateral curbs & 250 \\
Promiscuous paths (pedestrian + cyclist) & 250 (150 cyclist +100 pedestrian $)$ \\
Curbs width & $50 \mathrm{~cm}$ \\
Lateral marking signs & $20-25 \mathrm{~cm}$ \\
\hline
\end{tabular}

Table 5. Path slope.

\begin{tabular}{lc}
\hline \multicolumn{1}{c}{ Max Slope } & Max Extension $(\mathrm{m})$ \\
\hline Usual longitudinal slope $(\max 5 \%)$ & changing value \\
Longitudinal slope $(\max 12 \%)$ & $12 \mathrm{~m}$ \\
Longitudinal slope $(\max 6 \%)$ & $100 \mathrm{~m}$ \\
Transversal slope $(\max 2.5 \%)$ (for rainwater disposal) & changing value \\
\hline
\end{tabular}

Table 6. Traffic island widths.

\begin{tabular}{lc}
\hline \multicolumn{1}{c}{ Min Width } & (cm) \\
\hline Traffic island or green island & 50 \\
Curbs (for low speed) & 30 \\
\hline
\end{tabular}

Among the design standards, the following should be well kept and estimated in advance: minimum radii of curvature as a function of the design speed, which must never be less than $20 \mathrm{~km} / \mathrm{h}$, and visibility from afar.

- Operational speed: it is the travel speed of motorized vehicles in normal outflow conditions; as specified in point 1 of the methodology, the speeds taken as a reference are: $v_{1}<30 \mathrm{~km} / \mathrm{h}$, $\mathrm{v}_{2}=30-50 \mathrm{~km} / \mathrm{h}$, and $\mathrm{v}_{3}=50-70 \mathrm{~km} / \mathrm{h}$.

- Conflict point definition: in order to guarantee the safety and ride comfort for cyclists, both in the case of single and promiscuous lanes, different types of conflicts (lateral, longitudinal, and transversal) must be analyzed. Road junctions and crossings are the most critical points of a cycle network.

- Safety index: in the literature, there are numerous indicators that allow us to describe the safety of cycle paths, looking at conflict points, visibility between bicycles, and vehicles, but also regularity of the pavement and adequate lighting of the cycle paths. Here we relate to two indicators for the safety level, bicycle compatibility index (BCI) and bicycle level of service (BLOS), shown in Table 7. BCI (bicycle compatibility index) gives a synthetic judgment directly linked to the volume of traffic (bike/h), the speed of the vehicle flow $(\mathrm{m} / \mathrm{s}$ or $\mathrm{km} / \mathrm{h}$ ), and the width of the track or space available for cycle transit (m) [34]. It is also refers to other factors that influence the level of comfort (presence/absence of signs, volume of traffic that turns right, presence of car parks, presence of traffic dividers, etc.), in accordance with the Highway Capacity Manual (HCM) [35]. The BLOS (Bicycle Level Of Service) index 
expresses synthetically a judgment of darkness and ride comfort perceived by cyclists on the basis of traffic volumes and the geometric functional conditions of the infrastructure. In fact, it depends logarithmically on the volume of traffic, on the pavement conditions and on the presence of heavy vehicular traffic, while no correlation exists with the number of parking maneuvers and the volume of traffic that turns occupying the lane [36,37]. Yet, a sound design should consider all permitted maneuvers and all potential points of conflict among bikes and vehicles.

Table 7. Safety parameters and index [38].

\begin{tabular}{|c|c|c|}
\hline Index & Parameters & Comparison LOS/BLOS \\
\hline BLOS & $\begin{array}{l}\text { Average Daily Traffic (ADT) } \\
\text { Traffic volume } \\
\mathrm{N}^{\circ} \text { lane } \\
\text { Max speed } \\
\text { Pavement condition range }\end{array}$ & 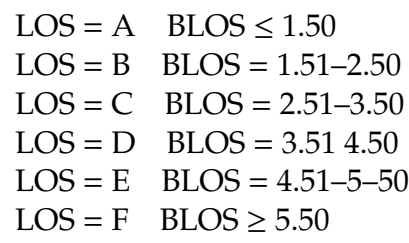 \\
\hline Index & Parameters & Comparison LOS/BCI \\
\hline BCI & $\begin{array}{l}\text { Presence of cycle path and roadside pavement } \\
\text { Presence of parking area and traffic islands } \\
\text { Cycle paths width or roadside pavement } \\
\text { Traffic volume related to the lane closed to sidewalk } \\
\text { or other lanes } \\
\text { Speed of traffic flow }(\mathrm{km} / \mathrm{h})\end{array}$ & $\begin{array}{ll}\text { LOS }=A & \text { BCI } \leq 1.50 \\
\text { LOS }=B & \text { BCI }=1.51-2.30 \\
\text { LOS }=\text { C } & \text { BCI }=2.31-3.40 \\
\text { LOS }=\mathrm{D} & \text { BCI }=3.41-4.40 \\
\text { LOS }=E & \text { BCI }=4.41-5.30 \\
\text { LOS }=F & \text { BCI } \geq 5.30\end{array}$ \\
\hline
\end{tabular}

5. Road pavement section and relative classification. Most of the cycle paths are made up of flexible or semi-rigid floors. In both cases, a bituminous mix is used for packaging the bonded layers of the structural package (binder layer and wear layer). They are located in the upper layers, but in this part there is the foundation layer, which in turn divides the loads towards the supporting ground (subgrade or subbase). In order to guarantee the stability and resistance of the cycle platform, the following materials and processes have been provided in the four proposed cases:

- Use of a geotextile. It is useful as a filter and as a separation layer, avoiding not only the contamination between materials of different grain size but also managing to maintain the physical-mechanical performance of the layers over time;

- Use of stabilized granular mixture for subbase/subgrade. It ensures adequate bearing capacity of the superstructure and at the same time provides a sufficiently level and regular surface for laying the upper layers;

- Use of dedusting pavement course [39]. It is applied on low-traffic roads to create a low-cost course, reducing the environmental impact. By reprofiling the laying surface, the dedusting phase consists of the first laying phase of a substance composed of diluted bituminous emulsion and crumbling, and secondly of a double emulsion/grit treatment.

The low viscosity bituminous emulsion penetrates the foundation and makes the laying surface cohesive and also ensures good adhesion to the subsequent multilayer treatment. It allows, in turn, the obtaining of a waterproof surface, to reduce dust in the dry season and avoid the formation of mud in the wet season:

- Use of treatment of the surface layer (single or double layer). This technique consists of a slim bitumen layer covered with a layer of monogranular material. To obtain a more resistant treatment, the binder/aggregate combination can be repeated by applying two or three monogranular layers (gradually decreasing in size), which are mutually united. 
The following pavement sections have been supposed not limited to:

- $\quad$ Pavement section with colored surface layer: as per Figure 2, the pavement section is a cohesive and waterproof wear layer (about $4 \mathrm{~cm}$ ), made of a mixture of different stones and grits according to the desired color effects, crushing sands, mineral additives (filler), colored pigments, hot mixed with a transparent oil-based binder. This layer is applicable in all situations in which low environmental impact chromatic effects are desired, compared to the traditional bituminous conglomerates used for the wear layers.

\section{COULORED SURFACE LAYER}

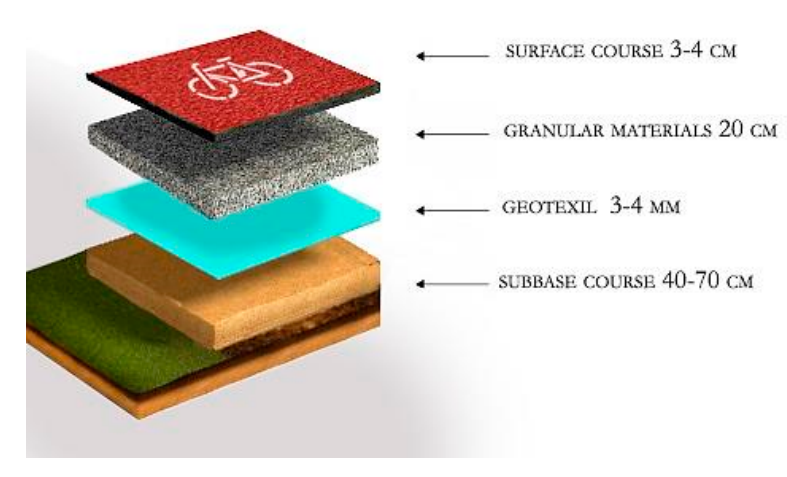

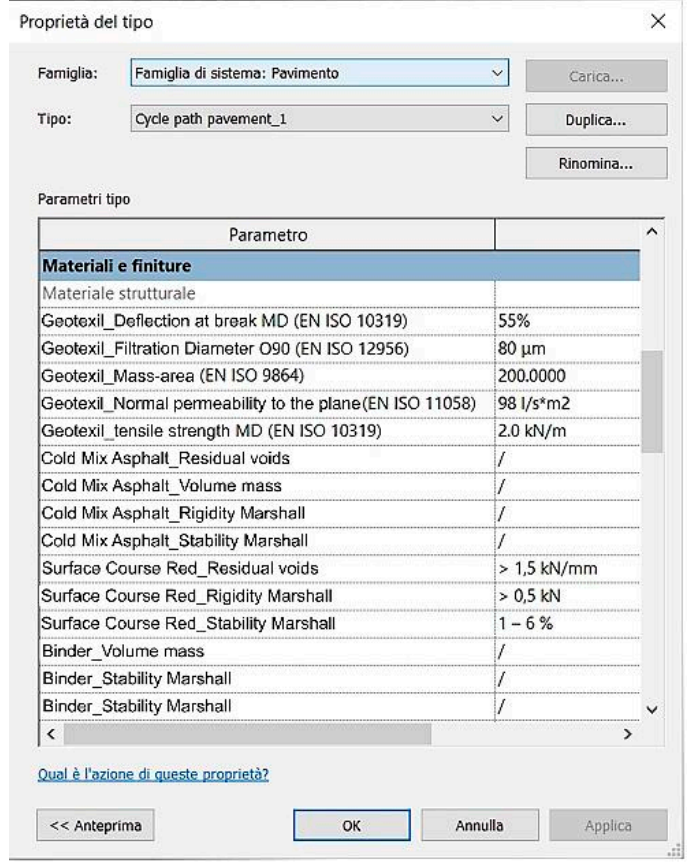

Figure 2. Pavement section with colored surface layer.

- Dust removal treatment in 3 steps (on surface layer of pavement section): as described in Figure 3, the layers are made of a bituminous emulsion with grit above the granular mixed layer. The first layer, with larger aggregates, makes the first centimeters of the granular mixed foundation layer cohesive and solid, while the other two layers, with smaller aggregates, seal the surface and, at the same time, give regularity.

- $\quad$ Single layer surface treatment: as shown in Figure 4, in order to give greater resistance to the superstructure, a layer of binder in traditional bituminous conglomerate (about $7 \mathrm{~cm}$ ) may be used, coupled with a single-layer surface treatment. To do so, the surface is treated with bituminous emulsion (bitumen modified with thermoplastic polymers) and quality grit, using a special equipment that can apply the bituminous emulsion and, immediately after, the grit in quantities according to the path's width, slope, and direction. Owing to this treatment, the surface gets a higher level of adherence and the pores of the underlying binder layer are sealed, guaranteeing greater water resistance.

- Double layer surface treatment: as described in Figure 5, on a layer of cold-recycled bituminous conglomerate (about $10 \mathrm{~cm}$ ), a milling of bituminous conglomerate is applied (70\%) and natural aggregates are used as granulometric correction for not more than $30 \%$. Alternatively cement and modified bituminous emulsion can be used. Owing to this treatment, the surface gets a higher level of adherence and the pores of the underlying binder layer are sealed, guaranteeing greater water resistance. 
ROAD DUST REMOVAL (3 STEP)

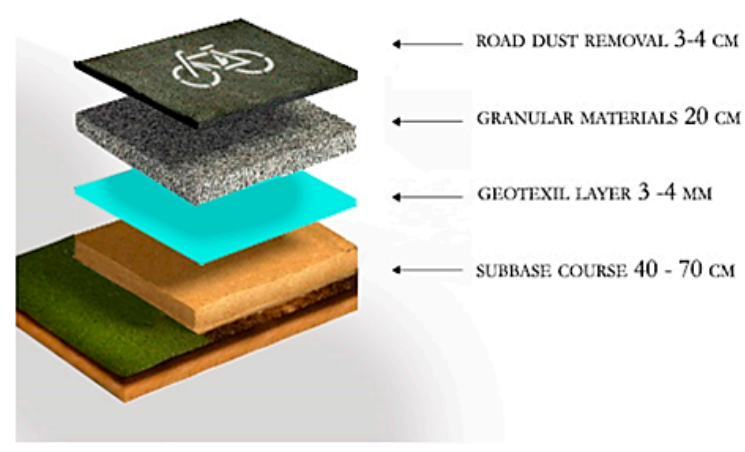

\begin{tabular}{|c|c|c|c|}
\hline \multicolumn{3}{|c|}{ Proprietà del tipo } & \\
\hline Fomiglia: & Fomiglia di sistema: Pavimento & corica... & \\
\hline \multirow[t]{2}{*}{ Tipo: } & Cyde path povement_2 & Duplica... & \\
\hline & & Rinomino... & \\
\hline \multicolumn{4}{|c|}{ Parametri tipo } \\
\hline \multicolumn{2}{|r|}{ Parametro } & & ^ \\
\hline \multicolumn{2}{|c|}{ Geotexil_Filtration Diameter O90 (EN ISO 12956) } & \multicolumn{2}{|l|}{$80 \mu \mathrm{m}$} \\
\hline \multicolumn{2}{|c|}{ GeotexilMass-area (EN ISO 9864) } & \multicolumn{2}{|l|}{200.0000} \\
\hline \multicolumn{2}{|c|}{ Geotexil_Normal permeability to the plane(EN ISO 11058) } & \multicolumn{2}{|l|}{$981 / s^{*} \mathrm{~m} 2$} \\
\hline \multicolumn{2}{|c|}{ Geotexil_tensile strength MD (EN ISO 10319) } & \multicolumn{2}{|l|}{$2.0 \mathrm{kN} / \mathrm{m}$} \\
\hline \multicolumn{2}{|c|}{ Cold Mix Asphalt_Residual voids } & \multicolumn{2}{|l|}{ I } \\
\hline \multicolumn{2}{|c|}{ Cold Mix Asphalt_Volume mass } & \multicolumn{2}{|l|}{ I } \\
\hline \multicolumn{2}{|c|}{ Cold Mix Asphalt_Rigidity Marshall } & \multicolumn{2}{|l|}{1} \\
\hline \multicolumn{2}{|c|}{ Cold Mix Asphalt_Stability Marshall } & \multicolumn{2}{|l|}{ I } \\
\hline \multicolumn{2}{|c|}{ Surface Course Red_Residual voids } & \multicolumn{2}{|l|}{ I } \\
\hline \multicolumn{2}{|c|}{ Surface Course Red_Rigidity Marshall } & \multicolumn{2}{|l|}{ I } \\
\hline \multicolumn{2}{|c|}{ Surface Course Red_Stability Marshall } & \multicolumn{2}{|l|}{ I } \\
\hline \multicolumn{2}{|c|}{ Binder_Volume mass } & \multicolumn{2}{|l|}{ I } \\
\hline \multicolumn{2}{|c|}{ Binder_Stability Marshall } & \multicolumn{2}{|l|}{ I } \\
\hline \multicolumn{2}{|c|}{ Binder_Stability Marshall } & \multicolumn{2}{|l|}{ I } \\
\hline \multicolumn{2}{|c|}{ Binder_Residual voids } & I & \\
\hline Bitumen & mulsion_Binder content & $63-67 \%$ & \\
\hline Bitumen & mulsion_Effect of water on adhesion & $>90 \%$ & \\
\hline Bitumen & mulsion_Rupture index & $70-130 \%$ & \\
\hline Bitumen & mulsion_Penetration at $25^{\circ} \mathrm{C}$ & $<100 \mathrm{dmm}$ & \\
\hline Bitumen & mulsion_Softening point & $>43^{\circ} \mathrm{C}$ & $\checkmark$ \\
\hline Qual d toz & he di queste propriets? & & \\
\hline$\ll$ Anter & Annullo & Applica & \\
\hline
\end{tabular}

Figure 3. Dust removal treatment on surface layer.

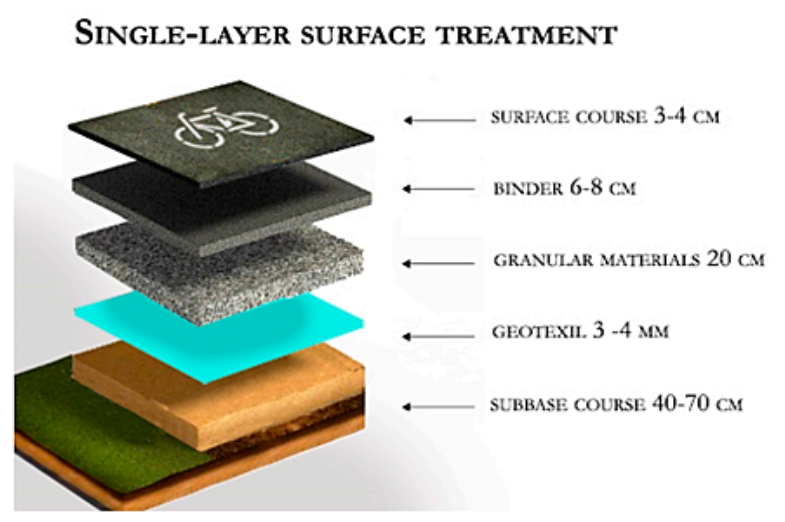

\begin{tabular}{|c|c|c|c|}
\hline \multicolumn{4}{|c|}{ Proprieta del tipo } \\
\hline Fomiglia: & \multicolumn{2}{|l|}{ Famiglio di sistema: Pavimento } & Carica... \\
\hline Tipo: & \multirow{2}{*}{\multicolumn{2}{|c|}{ Cyde poth poverment 3}} & Duplica... \\
\hline & & & Rinomino... \\
\hline \multicolumn{4}{|c|}{ Parametri tipo } \\
\hline \multicolumn{2}{|r|}{ Parametro } & & \\
\hline \multicolumn{2}{|c|}{ 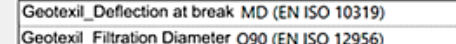 } & \multicolumn{2}{|l|}{$55 \%$} \\
\hline & \multicolumn{2}{|l|}{$80 \mu \mathrm{m}$} \\
\hline \multicolumn{2}{|c|}{ Geotexil_Mass-area (EN ISO 9864) } & \multicolumn{2}{|l|}{200.0000} \\
\hline \multicolumn{2}{|c|}{ Geotexil_Normal permeability to the plane(EN ISO 11058) } & \multicolumn{2}{|l|}{$981 / \mathrm{s}^{*} \mathrm{~m} 2$} \\
\hline \multicolumn{2}{|c|}{ Geotexil_tensile strength MD (EN ISO 10319) } & \multicolumn{2}{|l|}{$2.0 \mathrm{kN} / \mathrm{m}$} \\
\hline \multicolumn{2}{|c|}{ Cold_Mix Asphalt_Residual voids } & \multicolumn{2}{|l|}{1} \\
\hline \multirow{2}{*}{\multicolumn{2}{|c|}{$\begin{array}{l}\text { Cold Mix Asphalt_Volume mass } \\
\text { Cold_Mix Asphalt_Rigidity Marshall }\end{array}$}} & \multicolumn{2}{|l|}{1} \\
\hline & & \multicolumn{2}{|l|}{1} \\
\hline \multicolumn{2}{|c|}{ Cold Mix Asphalt_Stability Marshall } & \multicolumn{2}{|l|}{1} \\
\hline \multicolumn{2}{|c|}{ Surface Course Red_Residual voids } & \multicolumn{2}{|l|}{1} \\
\hline \multicolumn{2}{|c|}{ Surface Course Red_Rigidity Marshall } & \multicolumn{2}{|l|}{1} \\
\hline \multicolumn{2}{|c|}{ Surface Course Red_Stability Marshall } & \multicolumn{2}{|l|}{1} \\
\hline \multicolumn{2}{|c|}{ Binder_Volume mass } & \multicolumn{2}{|c|}{$2,40 \cdot 2,45 \mathrm{~g} / \mathrm{cm} 3$} \\
\hline \multicolumn{2}{|c|}{ Binder_Stability Marshall } & \multicolumn{2}{|l|}{$>3,0 \mathrm{kN} / \mathrm{mm}$} \\
\hline \multicolumn{2}{|c|}{ Binder_Stability Marshall } & $>15 \mathrm{kN}$ & \\
\hline Binder_f & esidual voids & $3-6 \%$ & \\
\hline Bitumen & mulsion_Binder content & $67 \cdot 71 \%$ & \\
\hline Bitumen & mulsion_Effect of water on adhesion & $>90 \%$ & \\
\hline Bitumen & mulsion_Rupture index & $70-155$ & \\
\hline $\mid \begin{array}{l}\text { Bitumen } \\
<\end{array}$ & emulsion_Penetration at $25^{\circ} \mathrm{C}$ & $<100 \mathrm{dmm}$ & \\
\hline Qual t roz & he d eveste propriets? & & \\
\hline$\ll$ Antep & ims & Annullo & Applico \\
\hline
\end{tabular}

Figure 4. Single layer surface treatment.

6. BIM implementation. In our hypothesis, the type sections and the technology packages defined above are implemented in BIM software, storing, and managing. The objective is to link all the data within the model so as to provide a picture of possible solutions for the performance related to each type of track chosen in relation to costs and pavement. Once the shared parameters have been chosen and the schedules created, they can be compiled in different ways: 
- Directly inside the model, manually filling in the sections related to the layer properties that appear once selected;

- If the data are provided in an external file, the preferred choice is a standard Excel file that can be easily compiled and imported later into the model that will automatically update with the new information.

\section{DOUBLE-LAYER SURFACE TREATMENT}

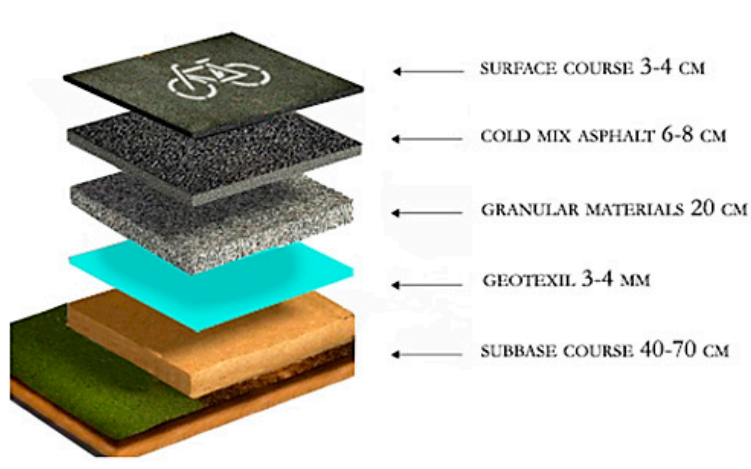

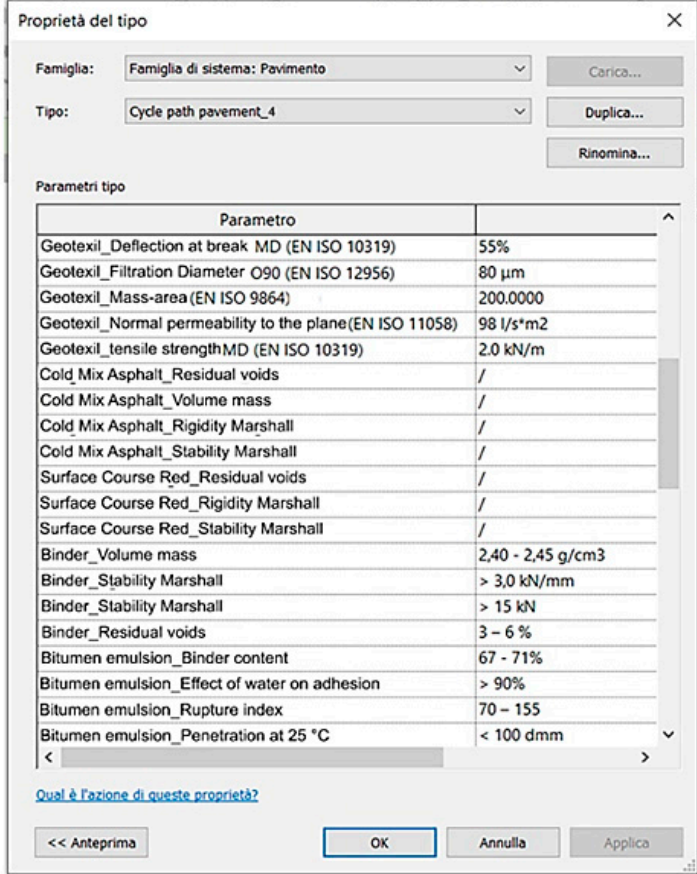

Figure 5. Double layer surface treatment.

7. Final evaluation. The final choice will be made through a logic explained in Figure 6:

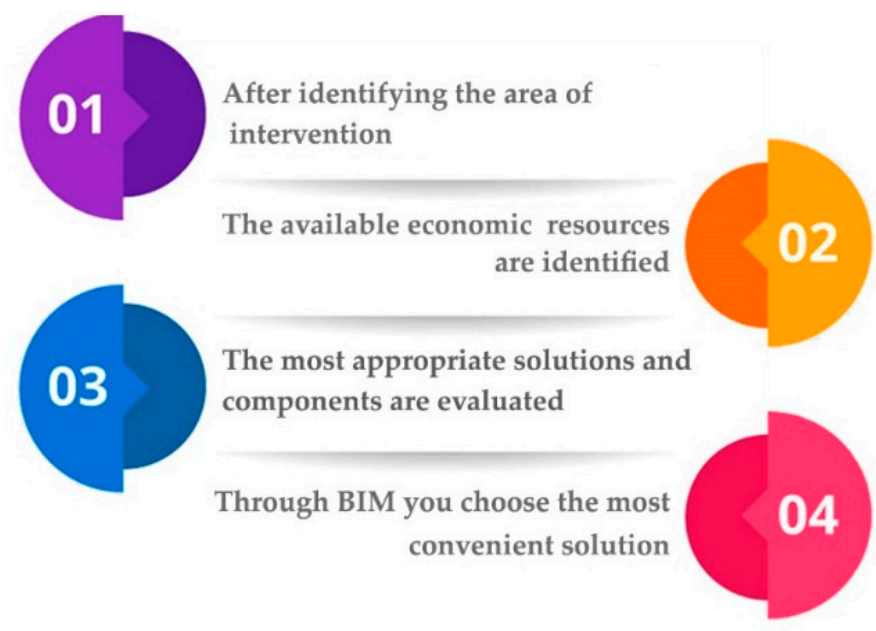

Figure 6. Flow chart methodology.

\section{Results}

We provide, as a non exhaustive example of implementation of the methodology introduced in the present paper, a case study referring to a situation which is widely spread in Italy. We chose Catania because, despite its geographical and demographic size, it does not have an efficient sustainable urban 
mobility system. Catania Metropolitan City is the second largest city in Sicily, after Palermo, and is its main industrial, logistical, and commercial center. It is located on the slopes of the Etna Mount and on its east side faces the Ionian Sea. The city's residents number about 300000, its area is about $180 \mathrm{~km}^{2}$ large, and its population density is about 1700 inhabitants $/ \mathrm{km}^{2}$. Unfortunately, there is no cycling network: occasional cyclists (mostly with a playful/sporting motivation) find space at the edge of lanes and on sidewalks, in dangerous promiscuity with vehicles and pedestrians. According to the general Urban Traffic Plan [39], the only bike paths on reserved lanes, officially established, are along Viale Kennedy, on Via Di Prima, and waterfront Europa-Ognina. However, these are itineraries without any connection to the town center and to different transport systems. Based on this background, we propose to plan a bike lane in one of the city's main roads, Corso Italia.

1. Localization of area of intervention. In the case study, the cycle path is designed in the following location:

- A1_A urban area with speed $<30 \mathrm{~km} / \mathrm{h}$

The cycle path originating from Viale XX Settembre, becoming later Corso Italia, would connect the historical center with the existing cycle path on the coast (see Figure 7). By zooming on one portion of the plan, we can see in Figure 8 the road section and its lanes. The total road width is $35 \mathrm{~m}$, divided into five lanes for vehicles (beginning from the left): three towards the sea and the last two (one for buses and taxis) towards the center. Among these are stalls for car parks and tree-lined sidewalks.

2. Economic availability. The designer will have to consider the economic constraints. For the sake of the example, we assumed that the choice should fall on one of three budget levels, defined as low-middle-high; the budget will dictate the construction and manufacturing materials to be used according to the construction requirements specified in the tender. We assumed a middle budget.

3. Cycle routes selection. The third step depends on the cycle path's functions. In the case study, we had

- Cycle path in a promiscuous cycle-pedestrian path, with the same direction of travel as vehicular traffic, located in an area where there are accesses and parking lots.

4. Standard design definition. The identification of the cycle path infrastructure location allows designers to select the best material combination according to the parameters proposed in Tables 3-5 above described. The cost is estimated in reference to a typical $1 \mathrm{~km}$ long segment placed in a straight line. The planimetric approach of the infrastructure allows designers to define the different types of straight and curved sections and to recalculate the entire route when the gradients vary.

5. Road pavement section and its classification. The choice of the different types of flooring will depend on the type of materials used and on cost. To choose the package, both the available budget and the best suited type for the case study should be taken into account. The methodology therefore considers 4 different flooring packages (defined respectively P1, P2, P3, and P4) with different implementation budgets defined as low-middle-high that divide each type of package into three subcategories. The choice of the package therefore stems from the combination of economic and design choices. In our case study we considered packages with middle cost.

6. BIM Revit software implementation. Revit allows users to create a three-dimensional model of the typological section considered, evaluating the best among different solutions. 


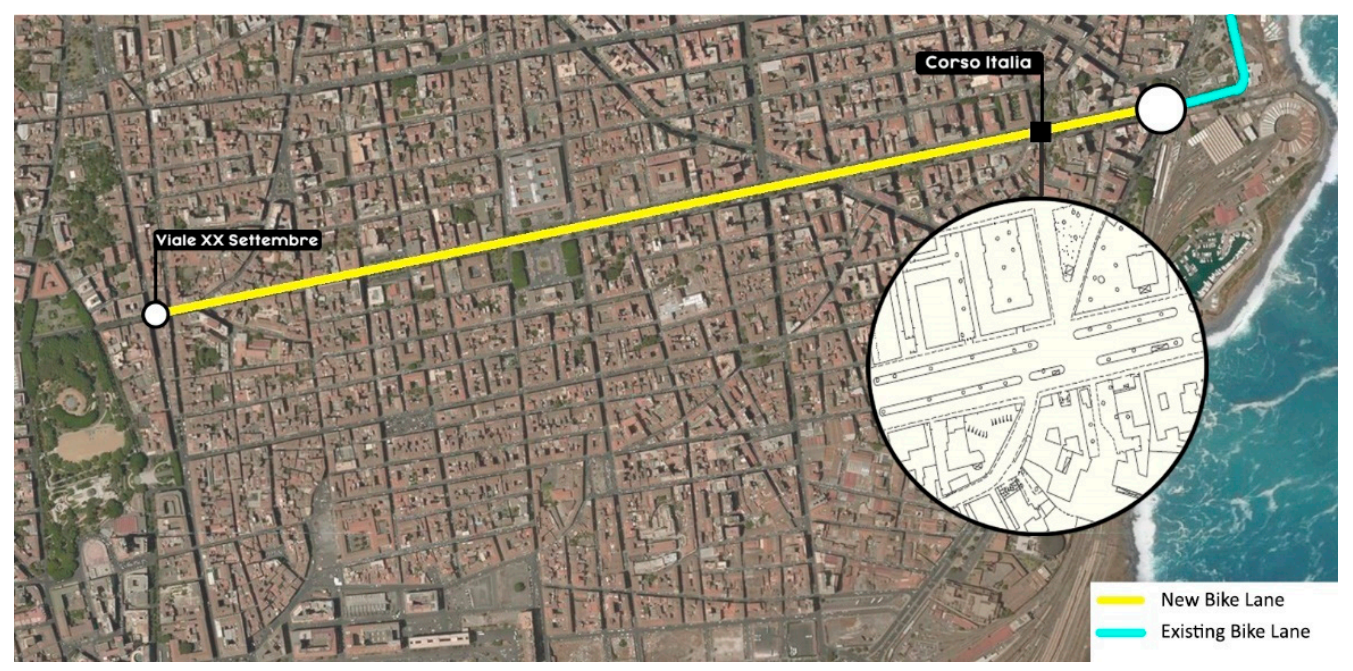

Figure 7. Design proposal.

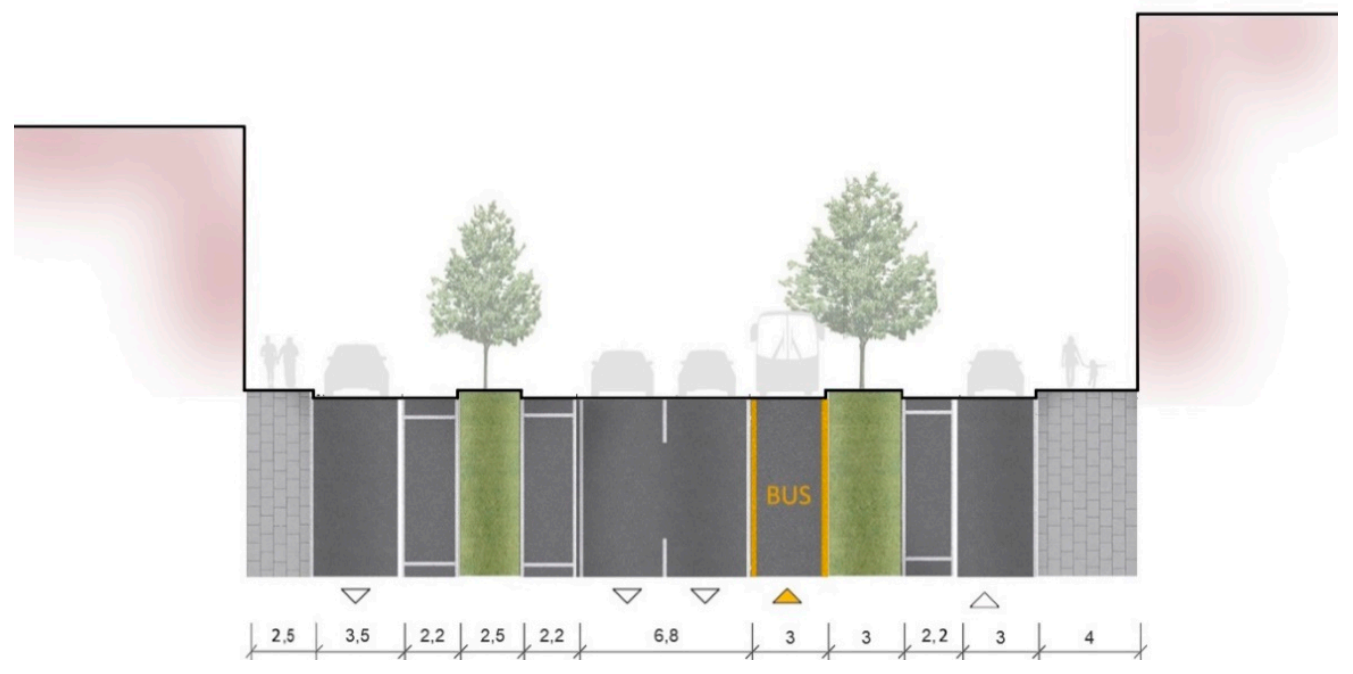

Figure 8. Road section at present.

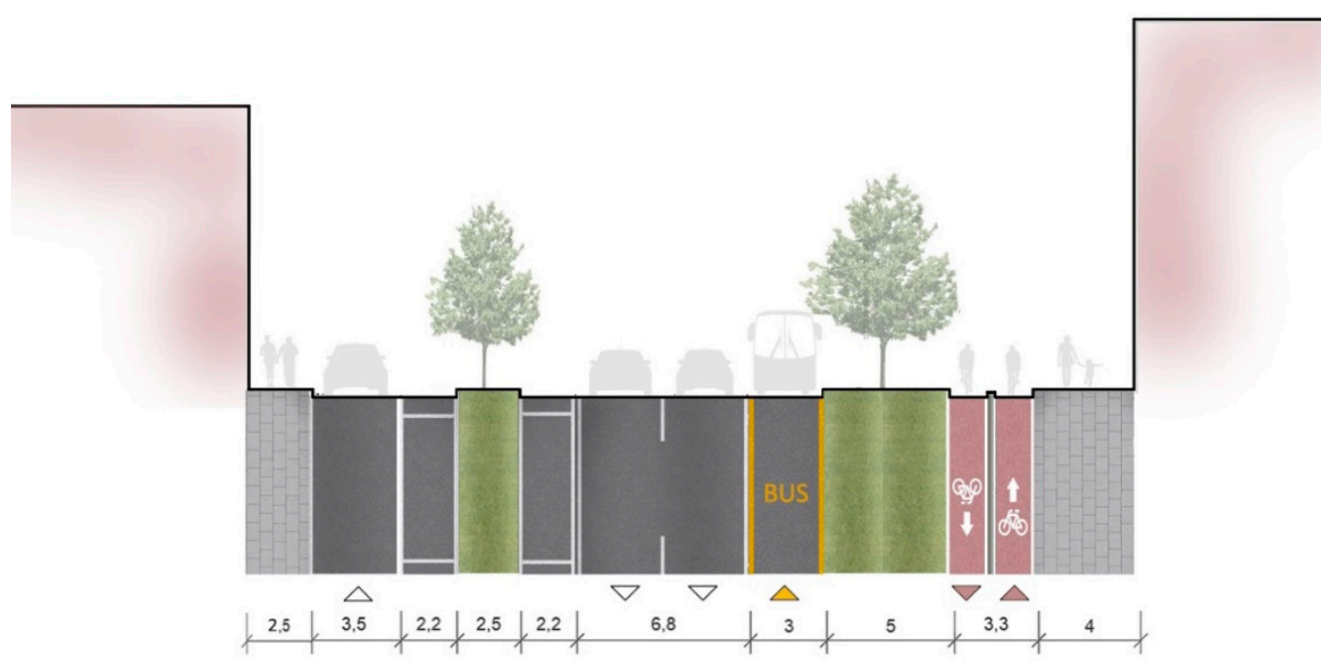

Figure 9. Design proposal road section. 
The requalification of monitored road infrastructure involved the variation of the vehicular flow directions in the lane on the left of the cross section proposed in Figures 8 and 9. Furthermore, the introduction of a double bidirectional cycle lane was considered (previously vehicular lane and parallel parking area) located near the sidewalk on the right. An analysis of vehicle flows through sensors and video cameras allowed the evaluation of the flows entering and leaving the historic center, implementing a strategy to promote sustainable mobility by reducing vehicle mobility. It took into consideration the outgoing flow smaller than that entering the historical center and envisaged the widening of the sidewalks for the removal of architectural barriers, implementation of public green spaces, and the use of micro mobility. The presence of the parking lots located on the right side of the infrastructure was reallocated to easily accessible neighboring areas.

Besides, shared parameters play a key role in a BIM design process because they can be called up through schedules and displayed in tabular form. They are updated in real time whenever a change is made by the user, who will be able to view the hypotheses with the relative ones through the creation of three schedules containing respectively:

- Geometrical-functional parameters;

- Safety parameters;

- Cost.

In Figure 10, by way of example, all the implemented parameters related to the first technology package are visible.

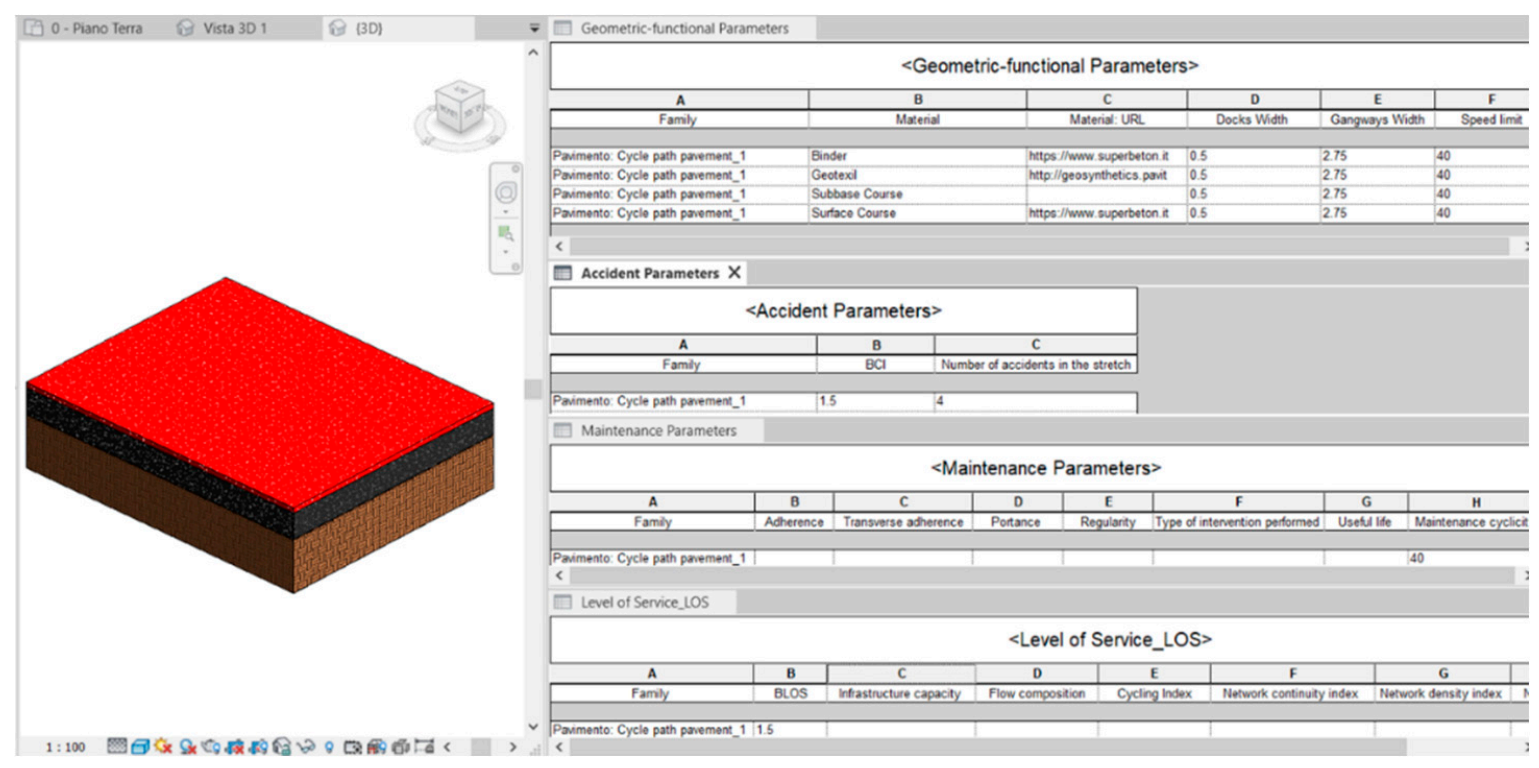

Figure 10. Parameters related to the three-dimensional model.

7. Final evaluation. The designer, after considering the functional geometrical aspect and selecting the eligible budget type, can evaluate which flooring package is the most suitable by looking at Table 8 . It also allows the designer to consider the safety standards, considering minimum acceptable values in terms of BLOS and BCI, and also to define an incident range from the number of conflict points generated by the selected geometric combination.

From the combination we can see how for a design in area A1 with a hypothesized schematization, and afferent to category R3, it will be necessary to maintain a safety standard not lower than a safety level B with a selection of flooring type P1 or P2 with a middle budget. 
Table 8. Project choice.

\begin{tabular}{|c|c|c|c|c|c|c|c|c|}
\hline \multirow{5}{*}{ Area } & \multirow{5}{*}{ ID } & \multicolumn{3}{|c|}{ Safety Index } & \multicolumn{4}{|c|}{ Pavement } \\
\hline & & \multirow{4}{*}{ Min BLOS } & \multirow{4}{*}{ Min BCI } & \multirow{4}{*}{$\begin{array}{l}\text { Supposed } \\
\text { Accidents }\end{array}$} & Colored Binder & Road Dust Removal & Single Layer & Double Layer \\
\hline & & & & & P1-Low & P2-Low & P3-Low & P4-Low \\
\hline & & & & & P1-Middle & P2-Middle & P3-Middle & P4-Middle \\
\hline & & & & & P1-High & P2-High & P3-High & P4-High \\
\hline \multirow{4}{*}{$\mathrm{A} 1$} & $\mathrm{R} 1$ & B & B & low number & \multicolumn{4}{|c|}{ P1—middle/P2—middle } \\
\hline & $\mathrm{R} 2$ & $\mathrm{C}$ & $\mathrm{C}$ & middle number & \multicolumn{4}{|c|}{$\mathrm{P} 1$-low/P2-low } \\
\hline & $\mathrm{R} 3$ & B & B & low number & \multicolumn{4}{|c|}{ P1—middle/P2—middle } \\
\hline & $\mathrm{R} 4$ & A & A & absence & \multicolumn{4}{|c|}{ P1—high/P2—high } \\
\hline \multirow{3}{*}{$\mathrm{A} 2$} & $\mathrm{R} 3$ & $\mathrm{~B}$ & $\mathrm{~B}$ & low number & \multicolumn{4}{|c|}{ P3—middle/P4—middle } \\
\hline & $\mathrm{R} 4$ & A & A & absence & \multicolumn{4}{|c|}{ P3-high/P4-high } \\
\hline & ${ }^{*} \mathrm{R} 5-{ }^{*} \mathrm{R} 6-{ }^{*} \mathrm{R} 7-{ }^{*} \mathrm{R} 8$ & $\mathrm{C}$ & $\mathrm{C}$ & middle number & \multicolumn{4}{|c|}{ P3—middle/P4—middle/P3—low/P4—low } \\
\hline \multirow{3}{*}{ A3 } & $\mathrm{R} 3$ & $\mathrm{~B}$ & $\mathrm{~B}$ & low number & \multicolumn{4}{|c|}{ P3—low/P4-low/P3-middle/P4—middle } \\
\hline & R4 & A & A & absence & \multicolumn{4}{|c|}{ P3—high/P4—high } \\
\hline & ${ }^{*} \mathrm{R} 7-{ }^{*} \mathrm{R} 8$ & B & $\mathrm{B}$ & low number & \multicolumn{4}{|c|}{ P3—middle/P4—middle } \\
\hline
\end{tabular}

${ }^{*}$ secondary design choices. 


\section{Discussion and Conclusions}

The COVID-19 pandemic has highlighted the need to control the movements of individuals and of urban transport; therefore, technological innovations such as APPs for smartphones and tablets based on geo-localization have been developed. This control system is also related to the new vision of transport that promotes greater connectivity among users, vehicles, and infrastructures. The growing concept of the mobility as a service (MaaS) promotes the implementation of mobility platforms, as developing a smart city involves the selection of a multimodal transport system.

The first step for such a selection is a careful evaluation of the design options and of the tools to control the process.

The main scientific contribution of this research is the definition of a methodology to carry out this evaluation by means of the I-BIM technology, which enables to consider cycle paths, processes, and systems, taking into account the entire life cycle of the infrastructure.

In fact, I-BIM can be used with great benefit in concepting and planning infrastructures during all the project's stages (preliminary, final, and executive). It also allows designers to compare different scenarios and create virtual simulations extremely close to reality, and to choose the best design option in terms of environmental impact, costs, and feasibility.

The methodology here presented can be easily replicated in different scenarios, considering not only elements related to cycle infrastructures but also to the other forms of mobility that coexist in the same infrastructure. Thanks to the step-by-step implementation, it allows maximum control of all phases of the design and construction of a project.

The first step of the proposed methodology focuses on the selection of the localization area of the cycle infrastructure by observing the urban variables (residential area or not) and the speed limits to be assumed. The second step is dedicated to identifying the best design choice from a functional-geometric point of view. The third and fourth phases instead allow designers to analyze the functional parameters of the building materials according to the different technologies.

At that stage, depending on the budget, using the tables presented above the designer can compare alternative solutions, correlating the BCI and BLOS indices with the characteristics of the flooring package. The creation of tables that correlate the different parameters has produced an example of the process by providing the user with an immediate evaluation tool that can assist during the plan choices selection. The uniqueness of the methodology lies in the ability to be able to collect, unify, and combine all the data, of different natures, concerning planning, design, and maintenance, allowing a control of all the stages of realization of an infrastructure work.

The health emergency dictated by COVID-19 offered the opportunity to review urban mobility considering the restart phase of production and commercial activities and also evaluating the best mobility model to prevent the contagion curve from rising again.

The evaluation of the case study related to the implementation of a cycle lane in the context of the city of Catania shows how the I-BIM approach is useful both for the implementation of the promoted choices of the SUMP (Sustainable Urban Mobility Plan), but also of the measures postpandemic for respecting the distancing of people.

In this vision, this study lays the basis for more in-depth research for bicycle path design and reconversion through the introduction of electric and micromobility, improving their use both for home-school and home-leisure travel reasons and discouraging the use of the private vehicles in accordance with sustainable mobility vision.

Author Contributions: Conceptualization, G.A. and T.C.; methodology, G.A. and T.C.; software, G.M.; formal analysis, T.C.; investigation, G.M.; resources and data curation, T.C.; writing-original draft preparation, G.A. and T.C.; writing - review and editing, G.A.; visualization and supervision, G.T. All authors have read and agreed to the published version of the manuscript.

Funding: This research work was partially funded by the MIUR (Ministry of Education, Universities and Research [Italy]) through a project entitled WEAKI TRANSIT. 
Acknowledgments: The authors acknowledge financial support from the MIUR (Ministry of Education, Universities and Research [Italy]) through a project entitled WEAKI TRANSIT: WEAK-demand areas Innovative TRANsport Shared services for Italian Towns (Project code: 20174ARRHT /CUP Code: J74I19000320008), financed with the PRIN 2017 (Research Projects of National Relevance) program. We authorize the MIUR to reproduce and distribute reprints for Governmental purposes, notwithstanding any copyright notations thereon. Any opinions, findings, and conclusions or recommendations expressed in this material are those of the authors and do not necessarily reflect the views of the MIUR.

Conflicts of Interest: The authors declare no conflict of interest.

\section{References}

1. Together-Your Home Base to Face Pediatric Cancer. Available online: https://together.stjude.org/en-us/ (accessed on 18 May 2020).

2. COVID-19: The Evolution of Bicycle and Pedestrian Activity Following Containment Measures-Eco-Counter. Available online: https://www.eco-compteur.com/en/blog/covid-19-the-evolution-of-bicycle-and-pedestrianactivity-following-containment-measures/ (accessed on 18 May 2020).

3. Kamel Boulos, M.N.; Geraghty, E.M. Geographical tracking and mapping of coronavirus disease COVID-19/severe acute respiratory syndrome coronavirus 2 (SARS-CoV-2) epidemic and associated events around the world: How 21st century GIS technologies are supporting the global fight against outbreaks and epidemics. Int. J. Health Geogr. 2020, 19, 8. [CrossRef] [PubMed]

4. Acampa, G.; Garcìa, J.O.; Grasso, M.; Diaz-Lopez, C. Project sustainability: Criteria to be introduced in BIM. Valori Valutazioni. 2019, N 23, 119-128.

5. Szigeti, S.; Csiszár, C.; Földes, D. Information Management of Demand-responsive Mobility Service Based on Autonomous Vehicles. Procedia Eng. 2017, 187, 483-491. [CrossRef]

6. Misso, F.E.; Pani, F.E.; Porru, S.; Repetto, C.; Sansone, U. Opportunities and boundaries of transport network telematics. In Proceedings of the 3rd World Congress on Civil, Structural, and Environmental Engineering, Budapest, Hungary, 8-10 April 2018.

7. Wong, Y.Z.; Hensher, D.A.; Mulley, C. Mobility as a service (MaaS): Charting a future context. Transp. Res. Part A Policy Pract. 2020, 131, 5-19. [CrossRef]

8. Canale, A.; Tesoriere, G.; Campisi, T. The MAAS development as a mobility solution based on the individual needs of transport users. AIP Conf. Proc. 2019, 2186, 160005. [CrossRef]

9. Földes, D.; Csiszár, C. Conception of future integrated smart mobility. In Proceedings of the 2016 Smart Cities Symposium Prague (SCSP), Prague, Czech Republic, 26-27 May 2016; pp. 1-6. [CrossRef]

10. Midgley, P.M. Bicycle-Sharing Schemes: Enhancing Sustainable Mobility in Urban Areas; Department of Economics and Social Affairs: New York, NY, USA, 2011.

11. O'Brien, O.; Cheshire, J.; Batty, M. Mining bicycle sharing data for generating insights into sustainable transport systems. J. Transp. Geogr. 2014, 34, 262-273. [CrossRef]

12. Pogačar, K.; Dežan, L.; Lamot, M.; Renčelj, M. Determinants of Bicycle Use among Student Population: Exploratory Research of Social and Infrastructure Factors. ASI 2020, 3, 6. [CrossRef]

13. Paschalidis, E.; Prodromou, M.; Basbas, S.; Politis, I. Investigation of Cyclists' Attitudes and Perceptions Towards other Road Users: Evidence from a Case Study in Thessaloniki, Greece. IJT 2017, 5, 33-46. [CrossRef]

14. Suárez Rojas, S.M.; Garcia Galindo, J.A. Análisis del Comportamiento de las dos Últimas Estrategias Comunicativas "Plan Bici" y "mi Estilo es bici" que Permiten la Viabilidad de la Actual Campaña de Enrique Peñalosa Londoño. Alcalde mayor de Bogotá Decreto 596 (2014). Sistema de Bicicletas Públicas. Recuperado de. Available online: http://www.alcaldiabogota.gov.co/sisjur/consulta_tematica.htm (accessed on 8 June 2016).

15. Nikiforiadis, A.; Basbas, S. Can pedestrians and cyclists share the same space? The case of a city with low cycling levels and experience. Sustain. Cities Soc. 2019, 46, 101453. [CrossRef]

16. Acampa, G.; Marino, G.; Ticali, D. Validation of infrastructures through BIM. AIP Conf. Proc. 2019, 2186, 160011. [CrossRef]

17. BIM Handbook: A Guide to Building Information Modeling for Owners, Managers, Designers, Engineers and Contractors, 2nd ed.; Eastman, C.M. (Ed.) Wiley: Hoboken, NJ, USA, 2011; ISBN 978-0-470-54137-1. 
18. Acampa, G.; Contino, F.; Grasso, M.; Ticali, D. Evaluation of infrastructure: Application of TOD to Catania underground metro station. AIP Conf. Proc. 2019, 2186, 160010. [CrossRef]

19. Acampa, G.; Crespo Cabillo, I.; Marino, G. Representación del dibujo frente a simulación de los sistemas BIM. Oportunidad o amenaza para la arquitectura. ACE Archit. City Environ. 2019, 14, 111. [CrossRef]

20. Acampa, G.; Forte, F.; De Paola, P.B.I.M. Models and Evaluations. In Values and Functions for Future Cities; Mondini, G., Oppio, A., Stanghellini, S., Bottero, M., Abastante, F., Eds.; Springer International Publishing: Cham, Switzerland, 2020; pp. 351-363. ISBN 978-3-030-23784-4. [CrossRef]

21. Dave, B.; Boddy, S.; Koskela, L. Challenges and opportunities in implementing lean and BIM on an infrastructure project. In Proceedings of the 21st Annual Conference of the International Group for Lean Construction 2013, IGLC 2013, Fortaleza, Brazil, 29 July-2 August 2013; pp. 741-750.

22. Sarkar, D. Risk Based Building Information Modeling (BIM) for Urban Infrastructure Transportation Project. Int. J. Struct. Constr. Eng. 2016, 10, 1022-1026.

23. Dell'Acqua, G. BIM per infrastrutture. Il Building Information Modeling per le grandi opere lineari; EPC Editore: Roma, Italy, 2018; p. 125. Available online: https://www.libroco.it/english/dl/Gianluca-Dell-Acqua/EPC/ 9788863108804/BIM-per-infrastrutture-Il-Building-Information-Modeling-per-le-grandi-opere-lineari/ cw989203458380784.html (accessed on 8 June 2020).

24. Lu, Q. Evaluation of the BIM Adoption for Civil Infrastructure and Development of a 5D BIM Financial Decision Making Framework; The Hong Kong University of Science and Technology: Clear Water Bay: Hong Kong, China, 2015; p. b1514765.

25. Holmström, J.; Singh, V.; Främling, K. BIM as Infrastructure in a Finnish HVAC Actor Network: Enabling Adoption, Reuse, and Recombination over a Building Life Cycle and between Projects. J. Manag. Eng. 2015, 31. [CrossRef]

26. Heikkilä, R.; Kaaranka, A.; Makkonen, T. Information Modelling Based Tunnel Design and Construction Process. In Proceedings of the 31st International Symposium on Automation and Robotics in Construction and Mining, Sydney, Australia, 9-11 July 2014; pp. 672-675.

27. Neves, J.; Sampaio, Z.; Vilela, M. A Case Study of BIM Implementation in Rail Track Rehabilitation. Infrastructures 2019, 4, 8. [CrossRef]

28. Liu, W.; Guo, H.; Li, H.; Li, Y. Retracted: Using BIM to Improve the Design and Construction of Bridge Projects: A Case Study of a Long-Span Steel-Box Arch Bridge Project. Int. J. Adv. Robot. Syst. 2014, 11, 125. [CrossRef]

29. Marzouk, M.; Hisham, M.; Ismail, S.; Youssef, M.; Seif, O. On the use of Building Information Modeling in Infrastructure Bridges. In Proceedings of the 27th International Conference on Applications of IT in the AEC Industry, Cairo, Egypt, 16-18 November 2010.

30. Chen, J.; Bulbul, T.; Taylor, J.E.; Olgun, G. A Case Study of Embedding Real-time Infrastructure Sensor Data to BIM. In Proceedings of the Construction Research Congress, Atlanta, GA, USA, 19-21 May 2014; American Society of Civil Engineers: Atlanta, Georgia, 2014; pp. 269-278. [CrossRef]

31. Bruhova Foltynova, H.; Braun Kohlova, M. Cost-Benefit Analysis of Cycling Infrastructure: A Case Study of Pilsen; Charles University Environment (Prague): Prague, Czech Republic, 2002.

32. Main, H.E. Cost-Benefit Analysis of Building Bicycle Lanes in Truro, Nova Scotia; Acadia University: Wolfville, NS, Canada, 2013.

33. CodiceAppalti.it-Codice Degli Appalti e Delle Concessioni (DLgs 50-2016). Available online: https: //www.codiceappalti.it/ (accessed on 14 May 2020).

34. Campisi, T.; Tibljaš, A.D.; Tesoriere, G.; Canale, A.; Rencelj, M.; Šurdonja, S. Cycling traffic at turbo roundabouts: Some considerations related to cyclist mobility and safety. Transp. Res. Procedia 2020, 45, 627-634. [CrossRef]

35. Implementing BIM for Infrastructure Guide|Autodesk. Available online: https://www.autodesk.com/ solutions/bim/hub/bim-for-infrastructure-implementation-guide (accessed on 14 May 2020).

36. Beura, S.K.; Bhuyan, P.K. Development of a bicycle level of service model for urban street segments in mid-sized cities carrying heterogeneous traffic: A functional networks approach. J. Traffic Transp. Eng. (Engl. Ed.) 2017, 4, 503-521. [CrossRef]

37. Renčelj, M.; Campisi, T.; Canale, A.; Tesoriere, G. The Developing Benefits of the Advance Space Line (ASL) Systems for Planning Safer Traffic Light Intersections; AIP Publishing LLC: Rhodes, Greece, 2019; p. 160007. 
38. Landis, B.W.; Vattikuti, V.R.; Brannick, M.T. Real-Time Human Perceptions: Toward a Bicycle Level of Service. Transp. Res. Rec. 1997, 1578, 119-126. [CrossRef]

39. Comune di Catania Piano Generale del Traffico Urbano. Comune di Catania. Available online: https: //www.comune.catania.it/il-comune/uffici/piano-generale-del-traffico-urbano/ (accessed on 7 January 2020).

(C) 2020 by the authors. Licensee MDPI, Basel, Switzerland. This article is an open access article distributed under the terms and conditions of the Creative Commons Attribution (CC BY) license (http://creativecommons.org/licenses/by/4.0/). 